Article

\title{
Three Generations of Intergenerational Transmission of Neighbourhood Context
}

\author{
Lina Hedman ${ }^{1, *}$ and Maarten van Ham ${ }^{2,3}$ \\ ${ }^{1}$ Centre for Research and Development, Uppsala University/Region Gävleborg, 80188 Gävle, Sweden; \\ E-Mail: lina.hedman@regiongavleborg.se \\ 2 Department of Urbanism, Faculty of Architecture and the Built Environment, Delft University of Technology, \\ 2600 GA Delft, The Netherlands; E-Mail: m.vanham@tudelft.nl \\ ${ }^{3}$ School of Geography and Sustainable Development, University of St Andrews, St. Andrews, KY16 9AL, UK \\ * Corresponding author
}

Submitted: 7 October 2020 | Accepted: 27 January 2021 | Published: 13 May 2021

\begin{abstract}
The literature on intergenerational contextual mobility has shown that neighbourhood status is partly 'inherited' from parents by children. Children who spend their childhood in deprived neighbourhoods are more likely to live in such neighbourhoods as adults. It has been suggested that such transmission of neighbourhood status is also relevant from a multiple generation perspective. To our knowledge, however, this has only been confirmed by simulations and not by empirical research. This study uses actual empirical data covering the entire Swedish population over a 25-year period, to investigate intergenerational similarities in neighbourhood status for three generations of Swedish women. The findings suggest that the neighbourhood environments of Swedish women are correlated with the neighbourhood statuses of their mothers and, to some extent, grandmothers. These results are robust over two different analytical strategies-comparing the neighbourhood status of the three generations at roughly similar ages and at the same point in time-and two different spatial scales. We argue that the finding of such effects in (relatively egalitarian) Sweden implies that similar, and possibly stronger, patterns are likely to exist in other countries as well.
\end{abstract}

\section{Keywords}

intergenerational transmission; low-income neighbours; neighbourhood; register data; Sweden

\section{Issue}

This article is part of the issue "Vicious Circle of Segregation: Understanding the Connectedness of Spatial Inequality across Generations and Life Domains" edited by Tiit Tammaru (University of Tartu, Estonia), Siiri Silm (University of Tartu, Estonia), Frank Witlox (Ghent University, Belgium), Maarten van Ham (Delft University of Technology, The Netherlands) and Madli-Johanna Maidla (University of Tartu, Estonia).

(C) 2021 by the authors; licensee Cogitatio (Lisbon, Portugal). This article is licensed under a Creative Commons Attribution 4.0 International License (CC BY).

\section{Introduction}

The literature on intergenerational transmission suggests that the socio-economic status of children is linked to that of their parents. A vast bulk of this literature has focused on issues such as class, occupation, education and earnings (for overviews see Black \& Devereux, 2011; D'Addio, 2007). Geography, or the quality of the residential environment, is another aspect of socio-economic status that may affect individual life chances in terms of occupation, education and earnings. For children, the spatial environment-a function of opportunities and decisions made by their parents-affect their future life chances and consequently their opportunities in terms of where to live. In a 2016 The Guardian newspaper article, the argument is brought home starkly:

[If] you are born poor in Britain, in a poor area, the chances are that you will remain poor for the rest of your life. If you are born rich, in a rich area, the 
likelihood is that you will find a way-or will have ways come to you-to stay wealthy and privileged throughout your life, and your children will do the same. (Hanley, 2016)

There is a small but growing literature on the intergenerational transmission of neighbourhood status. Several studies have been able to link the neighbourhood status of children to that of their parents. For example, based on data from the US, Vartanian, Buck, and Gleason (2007) show that childhood neighbourhood disadvantage is correlated with adult neighbourhood quality for those living in the lowest quality neighbourhoods. Sharkey $(2008,2013)$ and Pais (2017) come to similar conclusions, adding that intergenerational transmission of neighbourhood composition is especially prevalent among poor African-American families. In two separate studies, both using data from Sweden, Gustafson, Katz, and Österberg (2017) and van Ham, Hedman, Manley, Coulter, and Östh (2014) find that the neighbourhood status of children is correlated to that of parents and that immigrants are more likely than natives to remain in disadvantaged areas over two generations. Manley, van Ham, and Hedman (2020) add a family dimension to the analysis: children from the same family live more similar lives than unrelated individuals but the neighbourhood of origin has an independent effect on future residential careers. Using data from the Netherlands, de Vuijst, van Ham, and Kleinhans (2017) add that higher education can reduce intergenerational transmission but that this is less prevalent among the immigrant population. Nordvik and Hedman (2019), however, argue that in the Norwegian setting, higher education may function as a means of social mobility for people with an immigrant background in particular.

These studies all support the idea that neighbourhood outcomes are influenced by the residential histories of previous generations and hence that individual life opportunities are correlated not only with one's own neighbourhood experiences but also with the experiences of previous generations.

The intergenerational argument can be extended further in time so that the same family experiences similar neighbourhood environments for multiple generations. Sharkey (2013) argues that this might indeed be the case among poor African-American families in the US:

The problem of urban poverty...is not only that concentrated poverty has intensified and racial segregation has persisted but that the same families have experienced the consequences of life in the most disadvantaged environments for multiple generations. (Sharkey, 2013, p. 26, italics in original)

Sharkey provides compelling theoretical arguments to support his claim and he uses two-generation data from the US to simulate how many generations it would take a family from a poor neighbourhood to reach a more affluent environment (a full century, or five generations). However, the study is based on simulations and does not actually use data for more than two generations.

This is the first article, as far as we know, that empirically tests the hypothesis of multiple-generational transmission of neighbourhood status. Using detailed Swedish register data, we investigate the extent to which the neighbourhood statuses of young women are related to the neighbourhood environments of their mothers and grandmothers. Sweden is internationally known for its low level of income inequality, including relatively small differences between neighbourhoods (although socioeconomic residential segregation levels have rapidly increased; see Andersson \& Kährik, 2016). The country is also characterised by a welfare system which is set up to help people 'move up,' for example, by providing free education for all. This implies that social mobility (including mobility to more affluent neighbourhoods) is easier and more common in Sweden compared to other countries (see Nieuwenhuis, Tammaru, van Ham, Hedman, \& Manley, 2020). Hence, any patterns of multigenerational transmission of neighbourhood status in Sweden are likely to be generalisable to other countries with fewer opportunities for social mobility.

\section{Neighbourhood Deprivation and Affluence as Multigenerational Phenomena}

The literature on neighbourhood effects increasingly stresses the importance of timed effects, longer time frames and intergenerational transmission. Empirical analyses demonstrate that effects linger and that childhood neighbourhood exposure affects life chances of individuals well into adulthood (Chetty, Hendren, \& Katz, 2016; Galster \& Santiago, 2017; Hedman, Manley, \& van Ham, 2019; Hedman, Manley, van Ham, \& Östh, 2015; Sampson, Sharkey, \& Raudenbush, 2008; Sharkey, 2008). Sharkey and Elwert (2011) take the analysis one step further and show that cognitive abilities of children are substantially reduced (by more than half a standard deviation) if their families have been exposed to poverty for two consecutive generations. That is, children suffer negative effects from a residential environment they have not experienced themselves. Sharkey and Elwert's (2011) findings stress the importance to better incorporate multigenerational mechanisms into understanding the residential deprivation context which people live in. This need is further highlighted by the increasing empirical evidence of intergenerational transmission of living in impoverished neighbourhoods over two consecutive generations. More than $70 \%$ of the African-American children who grow up in the most deprived areas live in similar types of neighbourhoods also as adults (Sharkey, 2008, 2013). As mentioned in the introduction, the inheritance of living in poverty neighbourhoods is not restricted to the US but is also prevalent in countries with a very different welfare state arrangement, such as Sweden, Norway and the Netherlands (de Vuijst et al., 
2017; Gustafson et al., 2017; Manley et al., 2020; Nordvik \& Hedman, 2019; van Ham et al., 2014).

Whereas for a long time the multi-generational perspective was more or less missing in the segregation and neighbourhood effect literature, it is somewhat better represented in the broader literature on intergenerational transmission of socioeconomic status. In this literature, several theoretical and empirical papers have illustrated and empirically tested whether and how multigenerational transmission occurs (although the twogenerational perspectives dominate). A critical debate in the literature revolves around the question of to what extent grandparents influence their grandchildren directly, over and above parental influence. Much of the 'early' research argued that high social fluidity would result in null (Piketty, 2000; for empirical studies see Cherlin \& Furstenberg, 1992; Warren \& Hauser, 1997) or even negative (Becker \& Tomes, 1986) associations between grandparents and grandchildren once parental characteristics are controlled for. Although supported by some later studies (Bol \& Kalmijn, 2016), there are also several examples of work that have found evidence of direct grandparental influence, such as Hällsten's (2015) analysis of grades, length of education and cognitive abilities, using Swedish 1st and 2nd cousins (see also, e.g., Chan \& Boliver, 2013; Lindahl, Palme, Sandgren Massih, \& Sjögren, 2015; Modin, Erikson, \& Vagero, 2013). Mare (2011) suggests that multigenerational influence might be context-dependent (most of the early research focused on mid-19th century US) and adds that even if the main path of transmission is from one generation to the next (which is generally confirmed by empirical studies), a multigenerational approach is useful since the second generation will influence their children. Hence, regardless of whether grandparents' influence is direct or only indirect, the result will be multigenerational inequality.

The literature on multigenerational socio-economic transmission discusses several mechanisms through which parents and grandparents may exert an influence on their (grand)children's future outcomes (for lengthier discussions see Mare, 2011; Piketty, 2000). Many of these mechanisms should apply to the housing and neighbourhood fields. Among the most important mechanisms for the transmission of socioeconomic status and housing are economic transfers, either through inter-vivo transfers or as after-life inheritances (D'Addio, 2007; Hochstenbach, 2018; Mare, 2011). Such transfers may consist of (larger sums of) money passing between generations or direct investments in (grand)children's housing. Economic transfers are especially important for explaining entrance into the homeownership sector for those whose ancestors are owners themselves (Helderman \& Mulder, 2007). Transfers and investments provide the opportunity for older generations to directly influence the quality of the home and its surroundings, the timing of the purchase and the mortgage setup (Engelhardt \& Mayer, 1994). (Grand)children of renters and low-income earners, or of owners in more deprived neighbourhoods characterised by a smaller housing prize increase, naturally lack these advantages and are consequently less able to buy a home in more affluent neighbourhoods when first entering the housing market (Hochstenbach, 2018; Hochstenbach \& Boterman, 2015; Jenkins \& Maynard, 1983; Mulder \& Smits, 1999).

Besides direct economic transfers, (grand)parents also have an indirect influence on their (grand)children's socioeconomic status (and hence housing market resources). They transfer knowledge, abilities and 'cultural resources' (including, among other things, reading habits, engagement in 'high cultural activities' and language habits; see Bol \& Kalmijn, 2016), and function as role models, all of which may affect the (grand)child's socio-economic choices and performance. In their study of Danish grandchildren's education success, Møllegaard and Meier Jæger (2015) found effects of grandparents' cultural capital, but not economic or social capital, and argue that their results are expected in the Scandinavian context characterised by high levels of income redistribution and free education. Their results may however be less relevant for the costly housing sector. (Grand)parents also share some of their genetic setups with their (biological) (grand)children and may hence share genetic advantages or disadvantages concerning socio-economic status. According to findings by Rowe, Vesterdal, and Rodgers (1998), a substantial part of the variation in IQ, education level and income can be explained by heritability, i.e., genetic variance.

(Grand)parents are also likely to affect housingrelated norms, attitudes and behaviours of their (grand)children. It has been argued that children 'learn' what appropriate housing is and strive to reach the social housing status of their parents (and potentially also previous generations; see Helderman \& Mulder, 2007; Henretta, 1984). Socialisation is not only related to housing type but also the larger residential environment. It has been shown that parents and children tend to live in similar types of environments, such as the inner city, suburbs or the countryside (Blaauboer, 2011; Feijten, Hooimeijer, \& Mulder, 2008). By growing up in, or pay regular visits to, a certain type of environment, children internalise the characteristics of that kind of environment and imbed them into their own housing aspirations.

To sum up, we know from the literature that there is a strong link between the neighbourhood trajectories of parents and their children. Therefore, it is likely that the neighbourhood trajectories of grandparents influence the trajectories of their children, and subsequently of their grandchildren (either directly or indirectly, via the mid-generation). This could be due to aspects that are directly related to housing (such as direct investments in children's housing) or to the transmission of norms or resources that eventually affect housing and neighbourhood decisions. Mare (2011) also points to the importance of acknowledging demographic aspects. In the 
multigenerational context, issues of timing of birth and longevity become especially important. Physical distance and the degree of interaction are also likely to affect the (grand)parent-(grand)child relation, interactions and level of transmission. Figure 1 illustrates these different forms of transmission as well as the partly overlapping neighbourhood trajectories of grandparents, parents and (grand)children. The figure also shows how the influence of the parental neighbourhood lingers on from childhood into adulthood, which (potentially) results in the multigenerational transmission of neighbourhood status.

\section{Data and Methods}

The data we use for this study is derived from the GeoSweden database, which is owned by the Institute for Housing and Urban Research, Uppsala University and bought from Statistics Sweden. The database consists of a compilation of datasets covering demographic, geographic and socio-economic characteristics of all individuals registered in Sweden. It contains consecutive data starting in 1990, up to 2014 (at the point of investigation).

The population selected for the study includes all females who in 2002 were at least 20 years old, had left the parental home, and whose mother and maternal grandmother were alive in 2002 and no more than 75 years of age. The age restrictions of daughter and grandmother ensure that we only compare adult individuals whose living situation is independent of that of their parents, and who are not 'too old' to reduce the likelihood of having moved into elderly care centres. Also, the (young) women had to live in municipalities with more than 100,000 inhabitants to obtain a more geographically robust estimate of the neighbourhood environment. We restrict the population to the female line for reasons of simplicity and because females on average live longer than males. In addition to being alive and younger than 76 , the mother and grandmother must also live in Sweden in both 1990 and 2002 for the family to be in the research population. Unfortunately, this requirement excludes most of the immigrant population. The remaining immigrants in the research data mainly consist of people born in the neighbouring countries of Finland and Denmark. This is unfortunate given that previous research has found that non-western immigrants, or people with an immigrant background, are more likely than natives to remain in poverty areas over two generations (van Ham et al., 2014; for a US Black-White comparison see also Sharkey, 2008, 2013).

We employ two different analytical strategies for comparing the three generations. Strategy 1 is to compare the three generations at as similar ages as possible. Demographic features (age and related features such as partnership status and child-bearing) are among the most powerful predictors of both intra-urban mobility and neighbourhood sorting. Using the full range of data, we compare the neighbourhood status of the youngest generation (daughters) in 2014 to the mid-generation (mothers) in 2002 and the oldest generation (grandmothers) in 1990. However, even though we reduce the age gap as much as possible, given the data at hand, the three generations are still of very different ages, which may influence neighbourhood sorting processes: The daughters are in their late 30s (in 2014) whereas the grandmothers are in their early 60s (in 1990; see Table 1). However, we capture all three generations at working ages and at a point in life when mobility rates are low and hence argue that the comparison still has merit.

A downside of strategy 1 is that it is sensitive to structural changes. During the 24 years that have passed between 1990 and 2014, Sweden has gone through economic boom and bust periods and experienced

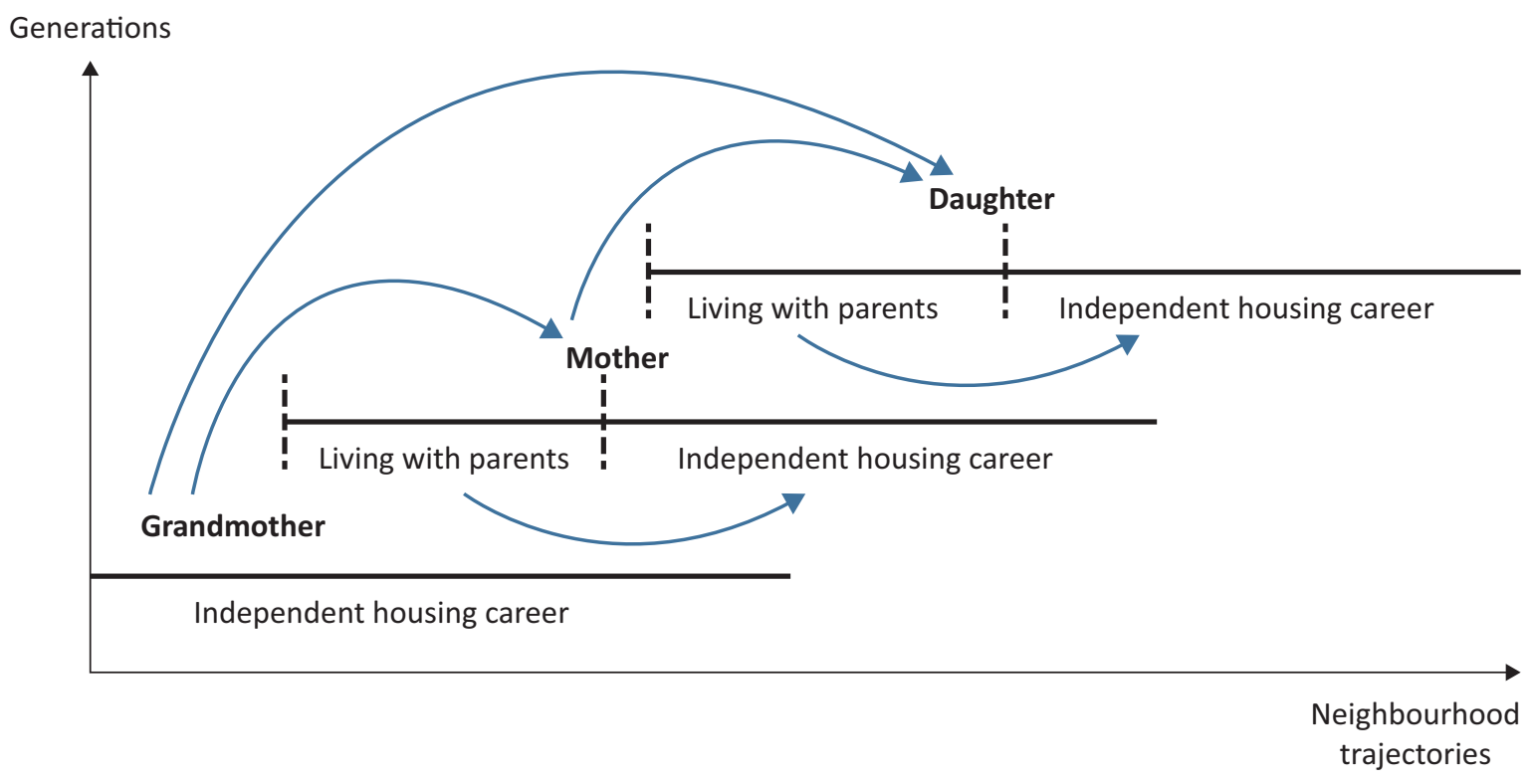

Figure 1. The linked lives across three generations. 
fundamental changes in welfare policies and life standards. In 1990, Sweden had almost full employment, with unemployment levels of about $1.5 \%$. During the crisis of 1992-1994, unemployment levels rose rapidly and have never fully recovered to their old level. High female participation in the labour force is a fundamental feature of the Swedish welfare state. Female employment levels are close to male employment levels and have been so through the entire period of study. However, the mother and in particular the grandmother generations are more likely than the younger women to have experienced spells of non-working and/or part-time working periods throughout their work-age career (housewives were a common feature of the 1950s and 1960s; Statistics Sweden, 2020) which obviously affects both their labour market status and their overall income situation.

Since the early 1990s, Sweden has witnessed a decline in welfare state arrangements, increasing inequality and increasing levels of privatisation. Between 1991 and 2013, the Gini Index has increased from 0.209 to 0.281 (OECD, 2021) due to increased capital gains and cuts in both tax levels and welfare redistributive systems. Residential segregation by income has increased accordingly, as a result of the increasing income gap and housing policy deregulations (Andersson, Magnusson Turner, \& Holmqvist, 2010). In short, tax reforms and changing political priorities have favoured owner-occupation over renting a home, resulting in a smaller rental sector (Grundström \& Molina, 2016). The housing surplus of the early 1990s changed into a housing shortage in most large cities in the early 2000s and prices have risen dramatically since the 1990s. Another important trend in Sweden as well as elsewhere is urbanisation. The total population has increased by almost 2 million people (21\%) since 1990, and the population increase has concentrated in urban areas. Cities are expanding spatially but the countryside, in general, has not experienced any particular population decline (with many variations across and between regions and places).

These and other changes on the macro level that may affect both the characteristics of neighbourhoods of different categories and the likelihood of different groups residing in them are controlled for in the second analytical strategy (strategy 2), which is to compare the three generations at the same point in time, in 2002. Obviously, the three generations are of very different ages (see Table 1) and they have furthermore had very different experiences up to this point but at least the macro-level situation at the point of comparison is the same. Each methodological strategy suffers from serious drawbacks but by combining both strategies, more robust conclusions can be drawn. Our data set encompasses 82,811 family lines using strategy 1 . With strategy 2 , the data set is slightly larger (due to more daughters living in large municipalities), encompassing 88,943 family lines.

To make neighbourhoods as comparable as possible, both over space and time, we make use of a $k$-nearest neighbour approach to define bespoke neighbourhoods.
Using the software EquiPop, we created bespoke neighbourhoods based on $k$-nearest neighbours. The neighbourhood computation is based on geographical coordinates, $100 \times 100 \mathrm{~m}$. For each coordinate pair, the software calculates the share of people of a certain characteristic among the $k$-nearest neighbours, by adding the population of surrounding coordinate pairs. In this study, we use the share of low-income people among the workingage population (20-64) as our neighbourhood variable. This share is based on income from work, including workrelated benefits. We argue that income from work, or the share with a low income from work, provides a good reflection of education and employment levels in the neighbourhood which are important signals of the neighbourhood's social status or deprivation level. This is especially true in countries (like Sweden) with high female labour participation rates. A low-income person is defined as someone whose income from work belongs to the three lowest deciles of the national distribution. This distribution is calculated separately for each year (1990, 2002 and 2014). We work with two different neighbourhood definitions, based on the 500 and 3,000 nearest neighbours, to control how transmission of neighbourhood status is related to geographic scale. The 500 nearest neighbours represent the immediate surrounding where the individual might know or recognise a substantial share of the neighbours. The 3,000 nearest neighbours scale aims to capture larger districts of shared local resources.

Descriptive statistics of the neighbourhood environments of daughters, mothers and grandmothers, using the two analytical strategies and the two geographical scales, are shown in Table 1 . The share of low-income people in the neighbourhood of the mother is equal using strategy 1 and 2: tautologically since the mother's neighbourhood environment is measured in the year 2002 using both research strategies. The grandmothers' neighbourhood status is also fairly similar over the two strategies, despite using strategy 1 in 1990 and strategy 2 in 2002. The daughters do, however, live in neighbourhoods with a lower share of low-income people using strategy 1 than strategy 2, on average. This is expected, given that the daughters are older using strategy 1 (measuring their neighbourhood status in 2014), about 37 years on average, compared to 25 using strategy 2 .

Table 1 also presents descriptive statistics for the control variables used in the linear regression model that will complement a set of descriptive tables and graphs. Using the share of low-income people in the neighbourhood of the daughter as the dependent variable, we model the effects of the share low-income neighbours of the mother and grandmother, controlling for the distance between daughter and mother/grandmother, the size of the municipality and several demographic and socio-economic variables, all measured as characteristics of the daughter. Distance is measured as Euclidean distance. Table 1 reveals that daughters and mothers live on average about $85 \mathrm{~km}$ from each other, 
Table 1. Descriptive statistics.

\begin{tabular}{|c|c|c|c|c|c|c|c|c|}
\hline & \multicolumn{4}{|c|}{500 nearest neighbours } & \multicolumn{4}{|c|}{3000 nearest neighbours } \\
\hline & \multicolumn{2}{|c|}{ Strategy 1} & \multicolumn{2}{|c|}{ Strategy 2} & \multicolumn{2}{|c|}{ Strategy 1} & \multicolumn{2}{|c|}{ Strategy 2} \\
\hline & Mean & Std Dev & Mean & Std Dev & Mean & Std Dev & Mean & Std Dev \\
\hline Age, daughter & 37.56 & 3.31 & 25.56 & 3.31 & 37.56 & 3.31 & 25.56 & 3.31 \\
\hline Age, mother & 51.13 & 4.71 & 51.13 & 4.71 & 51.13 & 4.71 & 51.13 & 4.71 \\
\hline Age, grandmother & 64.68 & 6.21 & 76.68 & 6.21 & 64.68 & 6.21 & 76.68 & 6.21 \\
\hline $\begin{array}{l}\text { \% Low-income neighbours, } \\
\text { daughters }\end{array}$ & 25.27 & 10.00 & 34.52 & 14.55 & 27.01 & 8.91 & 33.88 & 11.62 \\
\hline $\begin{array}{l}\% \text { Low-income neighbours, } \\
\text { mothers }\end{array}$ & 27.36 & 9.02 & 27.36 & 9.02 & 28.71 & 7.88 & 28.71 & 7.88 \\
\hline $\begin{array}{l}\text { \% Low-income neighbours, } \\
\text { grandmothers }\end{array}$ & 30.00 & 6.69 & 31.26 & 9.49 & 29.95 & 5.30 & 31.03 & 7.99 \\
\hline Distance daughter/mother (km) & 106.88 & 169.25 & 110.76 & 174.38 & 106.88 & 169.25 & 110.76 & 174.38 \\
\hline Distance daughter/grandmother (km) & 143.16 & 193.68 & 144.74 & 196.75 & 143.16 & 193.68 & 144.74 & 196.75 \\
\hline Family disposable income $(10,000$ SEK) & 5.90 & 4.62 & 1.84 & 2.19 & 5.90 & 4.62 & 1.84 & 2.19 \\
\hline $\begin{array}{l}\text { Education status, daughter } \\
\text { ( } 1=\text { lowest, } 4=\text { highest) }\end{array}$ & 3.01 & 1.11 & 2.56 & 1.04 & 3.01 & 1.11 & 2.56 & 1.04 \\
\hline \multicolumn{9}{|l|}{ Family status, daughter } \\
\hline single & \multicolumn{2}{|c|}{$18.92 \%$} & \multicolumn{2}{|c|}{$72.09 \%$} & \multicolumn{2}{|c|}{$18.92 \%$} & \multicolumn{2}{|c|}{$72.09 \%$} \\
\hline single w/ children & \multicolumn{2}{|c|}{$11.77 \%$} & \multicolumn{2}{|c|}{$4.99 \%$} & \multicolumn{2}{|c|}{$11.77 \%$} & \multicolumn{2}{|c|}{$4.99 \%$} \\
\hline couple & \multicolumn{2}{|c|}{$3.12 \%$} & \multicolumn{2}{|c|}{$4.24 \%$} & \multicolumn{2}{|c|}{$3.12 \%$} & \multicolumn{2}{|c|}{$4.24 \%$} \\
\hline couple w/ children & \multicolumn{2}{|c|}{$66.20 \%$} & \multicolumn{2}{|c|}{$18.68 \%$} & \multicolumn{2}{|c|}{$66.20 \%$} & \multicolumn{2}{|c|}{$18.68 \%$} \\
\hline
\end{tabular}

while grandmothers live on average slightly further away from their granddaughters (about $120 \mathrm{~km}$ ). Distances are slightly longer using strategy 2 . The demographic and socio-economic control variables are age, disposable family income, education level and family type. Education level is categorised into four types: less than 12 years of schooling, 12 years (equivalent to a high school degree), 13-14 years (some post-schooling) and $15+$ years (university degree). Family type is categorised into single, single with children, couple and couple with children.

\section{Results}

The main variables of interest in this study are the share low-income neighbours of daughter, mother and grandmother respectively. Table 2 displays the correlation coefficients of these respective variables, using strat- egy 1 and 2, and the two geographical levels. The table reveals, not surprisingly, that there is a stronger correlation between two consecutive generations-mother and daughter ( 0.12 to 0.21 ) and mother and grandmotherthan between grandmother and (grand)daughter ( 0.06 to 0.09 ). This is to be expected, partly because intergenerational transmission is assumed to be stronger between two consecutive generations, partly because of the data setup. The data better captures similar life stages for two consecutive generations, and/or more similar times. Comparing grandmothers to their granddaughters inevitably means either capturing them at very different ages (strategy 2; see Table 1) or at different times and still at rather different life stages (strategy 1 ). There are also differences depending on scale.

Correlations are generally stronger on the 3,000 nearest neighbour scale, indicating that whereas the immediate surroundings differ, the characteristics of the larger

Table 2. Correlation coefficients.

\begin{tabular}{lccccc}
\hline & \multicolumn{2}{c}{500 nearest neighbours } & & \multicolumn{2}{c}{3000 nearest neighbours } \\
\cline { 2 - 5 } & Strategy 1 & Strategy 2 & & Strategy 1 & Strategy 2 \\
\hline Daughters - Mothers & .1937 & .1194 & .2062 & .1714 \\
Daughters - Grandmothers & .0679 & .0590 & .0859 & .0916 \\
Mothers - Grandmothers & .1610 & .2082 & .1951 & .2674 \\
\hline
\end{tabular}


area are more similar. A possible interpretation is that the three generations' larger neighbourhoods have a similar place in the urban hierarchy, even though they may reside in different types of dwellings.

The share low-income neighbours of the daughter is the dependent variable in our regression models. Table 3 presents results on the 500 nearest neighbours scale using strategy 1 . Models I and II test how the share low-income neighbours of the daughter is correlated with that of the mother and the grandmother, respectively. Both correlations are positive, but with a larger coefficient for the mother in line with previous results. In model III, the share of low-income neighbours of both the mother and the grandmother are included. We find that the coefficients related to the mother are very similar to those of model I whereas those related to the grandmother are reduced compared to model II. The explanatory power of the model is also basically the same as for model I (0.137 in model III, compared to 0.135 for model I) whereas model II, including only the grandmother, was slightly weaker (0.114). This suggests that the neighbourhood of the mother is the most important to explain the outcome of the daughter whereas adding neighbourhood information of the grandmother only changes the outcome marginally.

The distance to the mother and the grandmother has little effect on the dependent variable. The other control variables work as expected. The likelihood of residing among a high share of low-income neighbours is negatively correlated with age, income and a higher level of education, whereas being single, with or without children, has a positive effect on the share of low-income neighbours. Not including controls leads to somewhat higher coefficients for the share low-income neighbours of both the mother and, to some extent, the grandmother, but (not surprisingly) to a much weaker model (model V).

The finding that the socioeconomic features of the daughter are the most important predictors of her neighbourhood composition is not surprising. It is similarly possible that the effect of the mother/grandmother neighbourhood composition is, in fact, a reflection of their socioeconomic situation. An intergenerational transmission of income would result in similar neighbourhood environments, through restricting housing market options of grandmothers, mothers and daughters. We test this by also adding the income of the mother and the grandmother to our model (model IV). However, the effect of these income variables is not significant, and the results do not change when removing the share of low-income neighbours of mother/grandmother to avoid collinearity issues (results not shown). These results suggest, in line with previous results of Sharkey (2008) and Nordvik and Hedman (2019), that intergenerational transmission of neighbourhood status is driven by neighbourhood context rather than income.

The relatively weak results for the grandmothers' influence are not very surprising keeping in mind that their residential environments are measured 24 years before those of their granddaughters. In fact, many of the grandmothers had already passed away when estimating the neighbourhood environments of the daughters. For this reason, we repeat the model III analysis using strategy 2 , comparing the three generations at the same point in time (see model $\mathrm{VI}$ ). The general pattern using strategy 2 is similar to strategy 1 : We find a clear positive correlation between the share of low-income neighbours of daughters and mothers, and of daughters and grandmothers, although the former relationship is substantially stronger. The size of the coefficients is however larger using strategy 2 for mothers and grandmothers alike. The explanatory power of the model is also substantially stronger (0.169). A possible explanation is that transmission is facilitated by time and timing. Strategy 2 measures direct transmission. Strategy 1 , however, requires that the effects on norms (including housing norms) and available resources last over long periods of time (12 years for mother/daughter, 24 years for grandmother/granddaughter). Another possible explanation is that daughters are more easily influenced at a younger age when they have a weaker social status (and may be more financially dependent on older generations) and have a less stable life position.

Models III and VI are repeated for the 3,000 nearest neighbours scale (see Supplementary File). The overall pattern is the same using the larger scale, but coefficients are bigger. Hence, the regression confirms the results of table 2 with stronger coefficients on the large geographical scale.

To better understand how the share low-income neighbours of the daughter is correlated with the share low-income neighbours of the mother and grandmother respectively, we have filled in the equation of model III (strategy 1, 500 nearest neighbours) using varying levels of the mothers' (Figure 2) or grandmothers' (Figure 3) low-income neighbours. We set the control variables to their mean levels, or modes for education (university degree) and family status (couple with children), and use two different estimates of the neighbourhood environment of the individual (mother or grandmother) whose neighbourhood environment is not shown on the $x$-axis. A high share of low-income neighbours (in the graph defined as a 'low-income neighbourhood') is equivalent to two standard deviations above the mean whereas a 'high-income neighbourhood' is a neighbourhood where the share low-income neighbours is set to two standard deviations below the mean. Figure 2 shows how the share low-income neighbours of the daughter is correlated with that of the mother, using the high- and low-income (grey and black lines respectively) neighbourhood scenarios of the grandmother, and the two different geographical scales (solid lines represent 500 nearest neighbours, dashed lines 3,000 nearest neighbours). The lines of Figure 2 are bundled very closely together, suggesting a very limited effect of geographical scale and, interestingly, whether 
Table 3. Linear regression model using strategy 1.

\begin{tabular}{|c|c|c|c|c|c|c|c|c|c|c|c|c|}
\hline & \multicolumn{10}{|c|}{ Strategy 1} & \multirow{2}{*}{\multicolumn{2}{|c|}{$\begin{array}{l}\text { Strategy } 2 \\
\text { Model VI }\end{array}$}} \\
\hline & \multicolumn{2}{|c|}{ Model I } & \multicolumn{2}{|c|}{ Model II } & \multicolumn{2}{|c|}{ Model III } & \multicolumn{2}{|c|}{ Model IV } & \multicolumn{2}{|c|}{ Model V } & & \\
\hline & Coeff & Std. Err. & Coeff & Std. Err. & Coeff & Std. Err. & Coeff & Std. Err. & Coeff & Std. Err. & Coeff & Std. Err. \\
\hline \% Low-income neighbours of mother & .1777 & .004 & & & .1714 & .004 & .1709 & .004 & .2053 & .005 & .1767 & .005 \\
\hline$\%$ Low-income neighbours of grandmother & & & .0905 & .005 & .0551 & .005 & .0558 & .005 & .0594 & .005 & .0749 & .005 \\
\hline Distance to mother (km) & .0005 & .000 & & & .0003 & .000 & .0003 & .000 & -.0003 & .000 & .0095 & .000 \\
\hline Distance to grandmother $(\mathrm{km})$ & & & .0005 & .000 & .0001 & .000 & .0002 & .000 & -.0001 & .000 & .0007 & .000 \\
\hline Age of daughter & -.1824 & .010 & -.2009 & .010 & -.1847 & .010 & -.1828 & .010 & -.2447 & .010 & -1.0581 & .030 \\
\hline $\begin{array}{l}\text { Family disposable income of } \\
\text { daughter (100 000 SEK) }\end{array}$ & -.1889 & .014 & -.1977 & .105 & -.1866 & .014 & -.1855 & .014 & & & -.4917 & .335 \\
\hline \multicolumn{13}{|l|}{ Education level of daughter (ref = LT12yrs) } \\
\hline $12 \mathrm{yrs}$ & -2.4753 & .126 & -2.7609 & .129 & -2.4658 & .126 & 2.4620 & .126 & & & -1.3888 & .129 \\
\hline $13-14$ yrs & -2.5461 & .139 & -2.8843 & .141 & -2.5274 & .138 & 2.5182 & .138 & & & 4.7398 & .151 \\
\hline $15+y r s$ & -2.6619 & .119 & -3.1180 & .121 & -2.6498 & .119 & 2.6386 & .199 & & & 2.4016 & .160 \\
\hline \multicolumn{13}{|l|}{ Family type daughter (ref = couple w/ children) } \\
\hline couple & 3.6311 & .202 & 3.7274 & .206 & 3.6409 & .202 & 3.6426 & .202 & & & 1.2015 & .238 \\
\hline single w/ children & 4.3526 & .126 & 4.5509 & .129 & 4.3629 & .126 & 4.3635 & .126 & & & 3.9374 & .591 \\
\hline single & 5.3953 & .110 & 5.5156 & .113 & 5.409 & .110 & 5.4126 & .110 & & & 3.3654 & .610 \\
\hline $\begin{array}{l}\text { Family disposable income of } \\
\text { mother (100 000 SEK) }\end{array}$ & & & & & & & -.0126 & .007 & & & & \\
\hline $\begin{array}{l}\text { Family disposable income of } \\
\text { grandmother (100 } 000 \text { SEK) }\end{array}$ & & & & & & & 18.0097 & 13.051 & & & & \\
\hline Constant & 28.9338 & .420 & 32.1067 & .433 & 27.5177 & .439 & 27.3810 & .462 & 27.0962 & .430 & 50.3118 & .619 \\
\hline $\mathrm{R} 2$ & \multicolumn{2}{|c|}{.135} & \multicolumn{2}{|c|}{.114} & \multicolumn{2}{|c|}{.137} & \multicolumn{2}{|c|}{.137} & \multicolumn{2}{|c|}{.046} & \multicolumn{2}{|c|}{.169} \\
\hline$N$ & \multicolumn{2}{|c|}{82,811} & \multicolumn{2}{|c|}{82,811} & \multicolumn{2}{|c|}{82,811} & \multicolumn{2}{|c|}{82,811} & \multicolumn{2}{|c|}{82,811} & \multicolumn{2}{|c|}{88,943} \\
\hline
\end{tabular}

Notes: Dependent variable = share low-income neighbours of daughter. All control variables relate to the daughter; 500 nearest neighbours. 


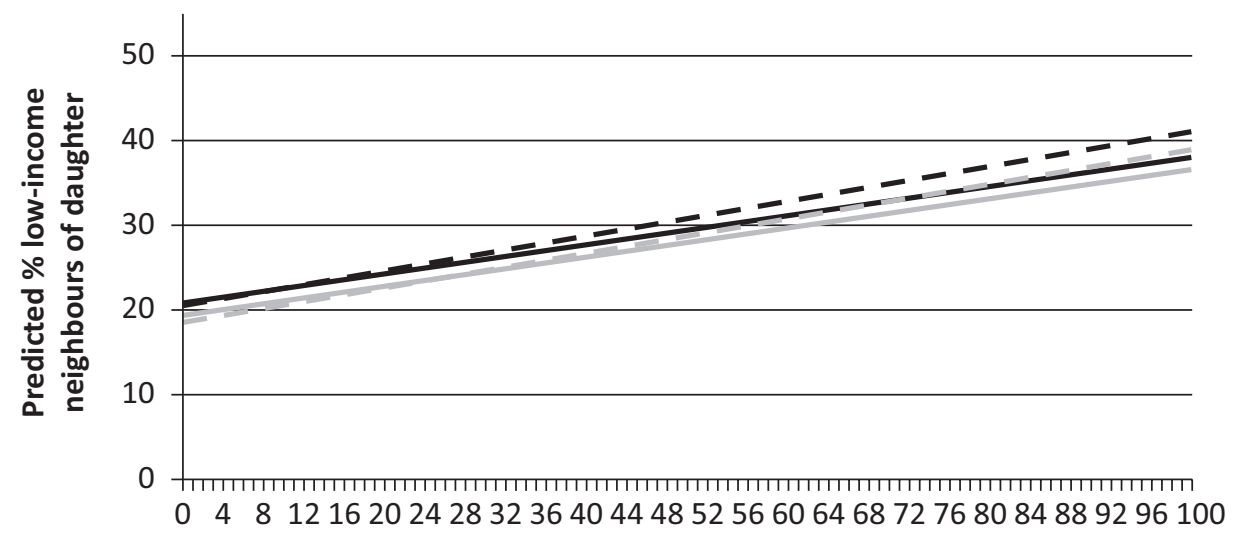

\% low-income neighbours of mother

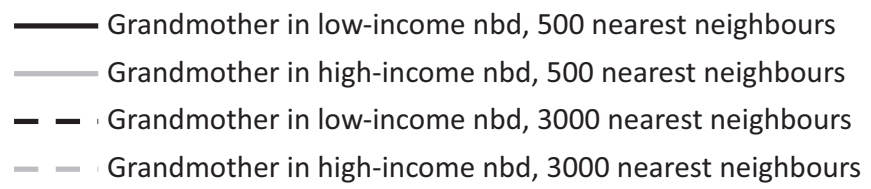

Figure 2. Predicted share low-income neighbours of the daughter by share low-income neighbours of the mother, for an individual of mean age, income and distance to mother/grandmother, mode education level and family status. Notes: Grandmother in high- or low-income neighbourhood, varying scale; strategy 1.

the grandmother lives in a high- or low-poverty neighbourhood, given the mother's neighbourhood composition. However, the grandmothers' neighbourhood environment is marginally correlated with that of their granddaughters: Daughters whose grandmothers live in high-income neighbourhoods live in areas with lower percentages low-income neighbours. The effect of the residential context of the mother is, however, relatively strong; as the share low-income neighbours of the mother increases from $0 \%$ to $100 \%$, the share lowincome neighbours of the daughter doubles (from about $20 \%$ to about $40 \%$ ). Figure 3 is equivalent to Figure 2 but shows the correlation between daughters and grandmothers, using two different neighbourhood scenarios of the mother. The graph confirms the limited extent of the grandmother's influence, given the neighbourhood environment of the mother. Changing the share low-income people in the grandmother's neighbourhood

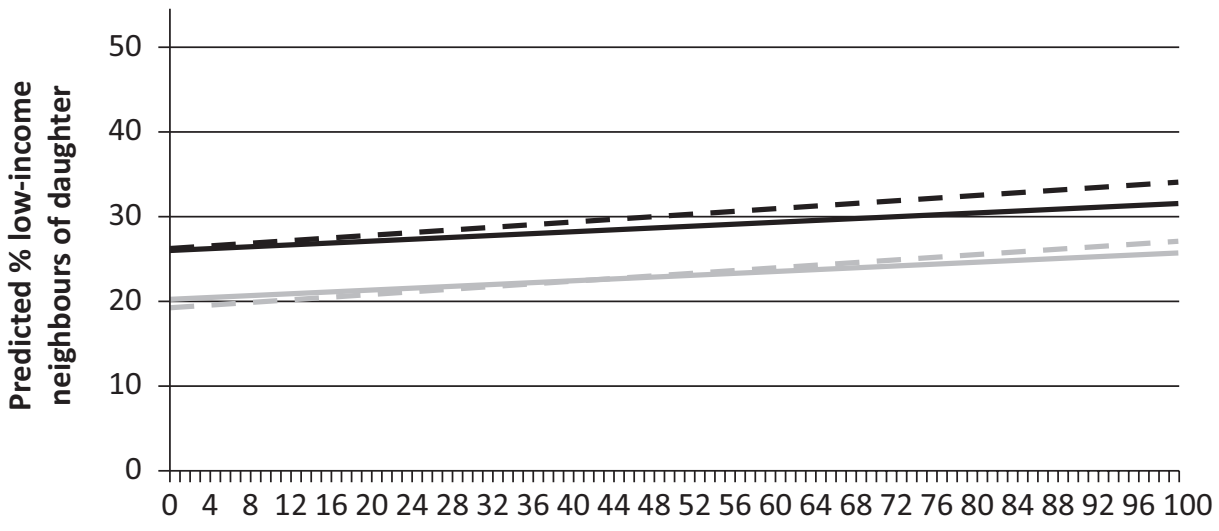

\% low-income neighbours of mother

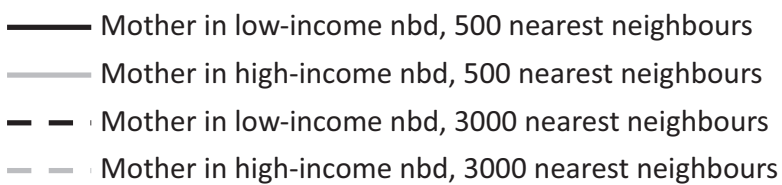

Figure 3. Predicted share low-income neighbours of daughter by share low-income neighbours of grandmother, for an individual of mean age, income and distance to mother/grandmother, mode education level and family status. Notes: Mother in high- or low-income neighbourhood, varying scale; strategy 1. 
from $0 \%$ to $100 \%$ will only result in a $5 \%$ increase in the share low-income neighbours of the (grand)daughter.

Repeating the same exercise but with the results of strategy 2 (model $\mathrm{VI}$ ), and an average strategy 2 individual, produces predicted shares of low-income neighbours that are higher-naturally since coefficients are larger and an average daughter in strategy 2 is younger, has a lower family income, a lower education level and is single (for means and modes using the two strategies, see Table 1). Whereas strategy 1 predicts that a daughter whose mother has $0 \%$ low-income neighbours and a grandmother in a high-income neighbourhood will have $19 \%$ low-income neighbours (see Figure 2), the equivalent number using strategy 2 is $27 \%$. Yet, despite differences in levels, strategy 2 yields a similar pattern (to Figure 2) when comparing mothers and daughters. The predicted share of low-income neighbours of the daughter increases by about 18 percentage points as the mother's share of low-income neighbours increases from $0 \%$ to $100 \%$ (compared to about 17 percentage points using strategy 1 ). Predictions are also very similar regardless of the grandmother's neighbourhood environment and geographical scale. The 3,000 nearest neighbour scale produces steeper lines, suggesting a stronger correlation with the mother/grandmother neighbourhood environment. The most probable explanation is scale effects. Segregation decreases on larger geographical scales, making areas more similar. It is also possible that a larger area better captures the neighbourhood surroundings. In densely populated areas, the 500 nearest neighbours may reside within a few building blocks, whose population composition does not necessarily capture the composition of the immediate area.

\section{Conclusion}

In this article, we set out to test the hypothesis that intergenerational transmission of neighbourhood status not only occurs from parents to children but is extended to multiple generations. Our findings suggest that transmission between two consecutive generations is substantially stronger than between grandmother and granddaughter, which is in line with previous literature on transmission of socio-economic status. Controlling for the neighbourhood environment of the mother, there is only a limited effect of the grandmother's residential environment on her granddaughter's location. However, rather than emphasising the marginal effect of the grandmother, it could be stressed that we do find empirical evidence for multigenerational transmission of neighbourhood status. Also, as argued by Mare (2011; see also Figure 1), multigenerational transmission could also be seen as multiple events of two-generational transmission where the elder generation influence their children, who in turn transmit their status to their children. Hence, the grandmother may have an additional indirect influence over the neighbourhood environment of her granddaughter. It should be stressed that our results do not measure causality. More research is needed to work out the causal transmission patterns and mechanisms over multiple generations. The findings of multigenerational correlations are however robust. They hold over different geographical scales and comparison strategies also when controlling for some of the most common predictors of where people live.

We find that comparing the three generations at the same point in time (i.e., at different points during the life course) yields stronger estimates than when comparing at as similar ages as possible but at different points in time. This is likely due to both timing and opportunities for the transfer of neighbourhood context. When estimating neighbourhood outcomes at the same time point, the youngest generation (daughters) is still very young - in their mid-20s-and hence more likely to be under parental influences. In their mid- to late 30 s (the age when we compare them at similar ages; strategy 1), most people have entered the labour market, started a family and moved into a more permanent home. The influence from older generations could be assumed to be smaller at that stage in life. Also, when comparing neighbourhood contexts at similar ages, the situation of the daughters is compared to that of their mothers' (12 years prior), and of their grandmothers' (24 years prior). Obviously, the (grand)parental influence diminishes with time, especially since many grandmothers are no longer alive at the time when we measure the (grand)daughters' neighbourhood environments. Rather than thinking in terms of small effects, one could argue that it is striking that we find even small correlations between the neighbourhood deprivation levels of adult women and their mothers and grandmothers, given the time that has passed. A third explanation for the smaller estimates of strategy 1 is that the structural situation has changed. The grandmothers' neighbourhood contexts are measured in 1990, at a time when Sweden experienced full employment, a strong welfare state, higher levels of equality and when housing policy was based on tenure neutrality. In 2014, there were higher levels of unemployment, segregation, income inequality and tenure inequality, with an increasing share of homeownership. Of course, the structural situation affects both the likelihood and the meaning of living among low-income neighbours. Hence, the incentives for daughters to avoid certain areas/neighbours may be different from those of their mothers and grandmothers.

The context also explains why the tentative multigenerational transmission of neighbourhood status is much lower in our study compared to the simulation by Sharkey for the US. Sweden has substantially lower levels of segregation, polarisation and poverty compared to the US. Also, most of our 'low-income neighbourhoods' (i.e., neighbourhoods with a share of low-income people among the nearest 500 or 3,000 neighbours) are most likely well-functioning areas inhabited by low-income workers. We might have found stronger patterns had the analysis been restricted to the poorest segments 
on the housing market. Another caveat is that for data reasons, our analysis is almost exclusively restricted to native Swedes and immigrant families from neighbouring Nordic countries. Non-western immigrants, a population group that is increasingly associated with poverty and residence in low-income areas and for whom two-generational transmission of neighbourhood status is strongest (van Ham et al., 2014), are absent in the analysis.

However, in a sense, these caveats only strengthen our results. We have found (weak) evidence of threegenerational transmission of neighbourhood status in a context where 'low-income neighbourhoods' are not characterised by extreme poverty and where a population group that is highly overrepresented in the most deprived areas is not included. We could thus expect patterns of transmission to become stronger in the future, in the context of both increasing levels of income segregation in Sweden and more multigenerational immigrant families.

Another caveat is that our analysis is restricted to females only and results may differ for males. It is also possible that results change if both the maternal and paternal lines are included. Maternal and paternal grandparents may live in a similar environment, which might strengthen multigenerational effects, or live in a very different environment, and hence 'compensate' for each other (the same is true for divorced parents). To look into all these complexities is a task for future research.

\section{Acknowledgments}

We would like to thank Tiit Tammaru (University of Tartu, Estonia) for his valuable input to this article. Lina Hedman worked at the Institute for Housing and Urban Research, Uppsala University, when most of the research presented in this article was conducted. The research leading to these results has received funding from the European Research Council under the European Union's Seventh Framework Programme (FP/2007-2013)/ERC Grant Agreement no. 615159 (ERC Consolidator Grant DEPRIVEDHOODS, socio-spatial inequality, deprived neighbourhoods, and neighbourhood effects).

\section{Conflict of Interests}

The authors declare no conflict of interests.

\section{Supplementary Material}

Supplementary material for this article is available online in the format provided by the author (unedited).

\section{References}

Andersson, R., \& Kährik, A. (2016). Widening gaps: Segregation dynamics during two decades of economic \& institutional change in Stockholm. In T. Tammaru, S.
Marcińczak, M. van Ham, \& S. Musterd (Eds.), Socioeconomic segregation in European capital cities. East meets West (pp. 110-131). London and New York, NY: Routledge.

Andersson, R., Magnusson Turner, L., \& Holmqvist, E. (2010). Contextualising ethnic residential segregation in Sweden: Welfare, housing and migrationrelated policies. In R. Andersson, H. Dhalmann, E. Holmqvist, T. M. Kauppinen, L. Magnusson Turner, H. Skifter Andersen, ... S. Yousfi (Eds.), Immigration, housing and segregation in the Nordic welfare states (pp. 81-126). Helsinki: University of Helsinki, Department of Geosciences and Geography.

Becker, G. S., \& Tomes, N. (1986). Human capital and the rise and fall of families. Journal of Labor Economics, $4(3), 1-39$.

Blaauboer, M. (2011). The impact of childhood experiences and family members outside the household on residential environment choices. Urban Studies, 48(8), 1635-1650.

Black, S. E., \& Devereux, P. J. (2011). Recent developments in intergenerational mobility. In O. C. Ashenfelter \& D. Card (Eds.), Handbook in labor economics (Vol. 4b, pp. 1487-1541). Amsterdam: Elsevier.

Bol, T., \& Kalmijn, M. (2016). Grandparents' resources and grandchildren's schooling: Does grandparental involvement moderate the grandparent effect? Social Science Research, 55, 155-170.

Chan, T. W., \& Boliver, V. (2013). Social mobility over three generations in Britain. American Sociological Review, 78, 662-678.

Cherlin, A. J., \& Furstenberg, F. F. (1992). The new American grandparent: A place in the family, a life apart. Cambridge, MA: Harvard University Press.

Chetty, R., Hendren, N., \& Katz, L. (2016). The effects of exposure to better neighborhoods on children: New evidence from the Moving to Opportunity experiment. American Economic Review, 106, 855-902.

D’Addio, A. C. (2007). Intergenerational transmission of disadvantage: Mobility or immobility across generations (OECD Working Paper No. 52). Paris: OECD Publishing.

de Vuijst, E., van Ham, M., \& Kleinhans, R. (2017). The moderating effect of higher education on intergenerational spatial inequality. Environment \& Planning $A$, 49(9), 2135-2154.

Engelhardt, G. V., \& Mayer, C. J. (1994). Gifts for home purchase and housing market behavior. New England Economic Review, 1994(May/June), 47-58.

Feijten, P., Hooimeijer, P., \& Mulder, C. H. (2008). Residential experience and residential environment choice over the life-course. Urban Studies, 45(1), 141-162.

Galster, G. C., \& Santiago, A. M. (2017). Do neighborhood effects on low-income minority children depend on their age? Evidence from a public housing natural experiment. Housing Policy Debate, 27, 584-610.

Grundström, K., \& Molina, I. (2016). From Folkhem to 
lifestyle housing in Sweden: Segregation and urban form, 1930s-2010s. International Journal of Housing Policy, 16(3), 316-336.

Gustafson, B., Katz, K., \& Österberg, T. (2017). Residential segregation from generation to generation: Intergenerational association in socio-spatial context among visible minorities and the majority population in metropolitan Sweden. Population Space \& Place, 23(4). https://doi.org/10.1002/psp.2028

Hällsten, M. (2015). Inequality across three and four generations in Egalitarian Sweden: 1st and 2nd cousin correlations in socio-economic outcomes. Research in Social Stratification and Mobility, 35, 19-33.

Hanley, L. (2016, September 27). Why class won't go away. The Guardian. Retrieved from https://www. theguardian.com/society/2016/sep/27/why-classwont-go-away

Hedman, L., Manley, D., \& van Ham, M. (2019). Using sibling data to explore the impact of neighbourhood histories and childhood family context on income from work. PLOS ONE, 14(5). https://doi.org/ 10.1371/journal.pone.0217635

Hedman, L., Manley, D., van Ham, M., \& Östh, J. (2015). Cumulative exposure to disadvantage and the intergenerational transmission of neighbourhood effects. Journal of Economic Geography, 15(1), 195-215.

Helderman, A., \& Mulder, C. H. (2007). Intergenerational transmission of homeownership: The roles of gifts and continuities in housing market characteristics. Urban Studies, 44(2), 231-247.

Henretta, J. C. (1984). Parental status and child's home ownership. American Sociological Review, 49(1), 131-140.

Hochstenbach, C. (2018). Spatializing the intergenerational transmission of inequalities: Parental wealth, residential segregation, and urban inequality. Environment and Planning A, 50(3), 689-708.

Hochstenbach, C., \& Boterman, W. R. (2015). Intergenerational support shaping residential trajectories: Young people leaving home in a gentrifying city. Urban Studies, 54(2), 399-420.

Jenkins, S. P., \& Maynard, A. K. (1983). Intergenerational continuities in housing. Urban Studies, 20(4), 431-438.

Lindahl, M., Palme, M., Sandgren Massih, S., \& Sjögren, A. (2015). Long-term intergenerational persistence of human capital an empirical analysis of four generations. Journal of Human Resources, 50(1), 1-33.

Manley, D., van Ham, M., \& Hedman, L. (2020). Inherited and spatial disadvantages: A longitudinal study of early adult neighborhood careers of siblings. Annals of the American Association of Geographers, 110(6), 1670-1689.

Mare, R. D. (2011). A multigenerational view of inequality. Demography, 48, 1-23.

Modin, B., Erikson, R., \& Vagero, D. (2013). Intergenerational continuity in school performance: Do grandparents matter? European Sociological Review, 29(4),
858-870.

Møllegaard, S., \& Meier Jæger, M. (2015). The effect of grandparents' economic, cultural, and social capital on grandchildren's educational success. Research in Social Stratification and Mobility 42, 11-19.

Mulder, C. H., \& Smits, J. (1999). First-time homeownership of couples: the effect of inter-generational transmission. European Sociological Review 15(3), 323-337.

Nieuwenhuis, J., Tammaru, T., van Ham, M., Hedman, L., \& Manley, D. (2020). Does segregation reduce sociospatial mobility? Evidence from four European countries with different inequality and segregation contexts. Urban Studies, 57(1), 176-197.

Nordvik, V., \& Hedman, L. (2019). Neighbourhood attainment of children of immigrants in Greater Oslo: Intergenerational inertia and the role of education. Population, Space and Place, 25(3). https://doi.org/ $10.1002 / p s p .2192$

OECD. (2021). Income distribution and poverty. OECD Stats. Retrieved from http://stats.oecd.org/Index. aspx?DataSetCode=IDD\#

Pais, J. (2017). Intergenerational neighborhood attainment and the legacy of racial residential segregation: A causal mediation analysis. Demography, 54, 1221-1250.

Piketty, T. (2000). Theories of persistent inequality and intergenerational mobility. Handbook of Income Distribution, 1, 429-476.

Rowe, D. C., Vesterdal, W. J., \& Rodgers, J. L. (1998). Herrnstein's syllogism: Genetic and shared environmental influences on iq, education, and income. Intelligence, 26(4), 405-423.

Sampson, R. J., Sharkey, P., \& Raudenbush, S. W. (2008). Durable effects of concentrated disadvantage on verbal ability among African-American children. Proceedings of the National Academy of Sciences, 105(3), 845-853.

Sharkey, P. (2008). Intergenerational transmission of context. American Journal of Sociology, 113(4), 931-969.

Sharkey, P. (2013). Stuck in place: Urban neighborhoods and the end of progress toward racial equality. Chicago, IL: University of Chicago Press.

Sharkey, P., \& Elwert, F. (2011). The legacy of disadvantage: Multigenerational neighborhood effects on cognitive ability. American Journal of Sociology, 116(6), 1934-1981.

Statistics Sweden. (2020). Women and men in Sweden. Facts and figures. Statistics Sweden. Retrieved from www.scb.se/hitta-statistik/statistik-efter-amne/ levnadsforhallanden/jamstalldhet/ jamstalldhetsstatistik/pong/publikation

van Ham, M., Hedman, L., Manley, D., Coulter, R., \& Östh, J. (2014). Intergenerational transmission of neighbourhood poverty in Sweden. An innovative analysis of individual neighbourhood histories. Transactions of the Institute of British Geographers, 39(3), 412-417. 
Vartanian, T. P., Buck, P. W., \& Gleason, P. (2007). Intergenerational neighborhood-type mobility: Examining differences between Blacks and Whites. Housing Studies, 22(5), 833-856.
Warren, J. R., \& Hauser, R. M. (1997). Social stratification across three generations: New evidence from the Wisconsin longitudinal study. American Sociological Review, 62, 561-572.

\section{About the Authors}

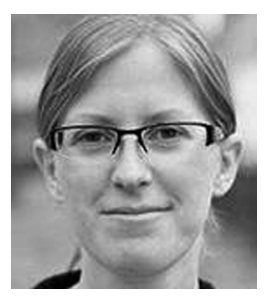

Lina Hedman holds a PhD in Human Geography from Uppsala University. She worked for many years as a researcher at the Institute for Housing and Urban Research, Uppsala University, but is currently employed by the Centre for Research and Development, Uppsala University/Region Gävleborg. Her main research interests include residential segregation, residential mobility and neighbourhood effects. She has published several studies on intergenerational patterns of neighbourhood inequality.

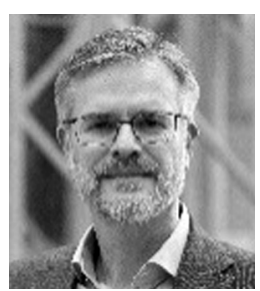

Maarten van Ham is Professor of Urban Geography at Delft University of Technology and Professor of Geography at the University of St. Andrews. He holds a PhD in Geography from Utrecht University (2002, Cum Laude). Maarten has published over 100 academic papers and 10 edited books. His main research interests include urban poverty and inequality, segregation, residential mobility and migration, neighbourhood effects, and urban and neighbourhood change. 